\section{Aortitis in patients with psoriatic arthropathy: report of two cases and review of the literature}

\author{
Gleb Slobodin, ${ }^{1,2}$ Ali Khateeb, ${ }^{1}$ \\ Doron Rimar, 2,3 Nina Boulman,2,3 \\ Michael Rozenbaum,, 2,3 Itzhak Rosner,2,3 \\ Lisa Kaly, ${ }^{3}$ Majed Odeh ${ }^{1,2}$
}

'Department of Internal Medicine A, Bnai

Zion Medical Center, Haifa; ${ }^{2}$ Ruth \& Bruce

Rappaport Faculty of Medicine, Technion, Haifa; ${ }^{3 R h e u m a t o l o g y ~ U n i t, ~ B n a i ~ Z i o n ~}$

Medical Center, Haifa, Israel

\begin{abstract}
Aortitis, which is well described in patients with other spondyloarthritides, has been rarely cited in relation to psoriatic arthropathy (PsA). Two patients with known PsA, who developed aortitis, are reported herein. The PubMed database was searched using the following keywords: aortitis, Takaysu arteritis, PsA, ankylosing spondylitis, reactive arthritis, inflammatory bowel disease. The relevant articles were critically reviewed and pertinent data organized. Analysis of 5 cases of aortitis in patients with PsA, including the 2 cases reported herein, revealed no specific pattern of PsA joint involvement in the patients who developed aortitis. All aortic segments can be involved and complications, such as insufficiency of the aortic valve and stenosis of the major aortic branches, have been described. The genetic association involving the IL12B locus may be involved in the clinical association of aortitis and spondyloarthritis.
\end{abstract}

\section{Introduction}

The aorta may be involved as in a variety of inflammatory rheumatic diseases. ${ }^{1}$ The clinical presentation of aortic wall inflammation, or aortitis, is not specific in the majority of the patients and is usually manifested by general symptoms such as fever, malaise, and non-specific pain, frequently accompanied by elevated levels of serum C-reactive protein (CRP) and erythrocyte sedimentation rate (ESR). Aortic valve insufficiency, organ ischemia and acute life-threatening aortic syndromes, such as aortic dissection or rupture, can complicate the course of aortitis in some patients. As such, aortitis is a well-known manifestation of spondyloarthritis. And yet, while reported in up to $10 \%$ of patients with long-standing ankylos- ing spondylitis (AS), aortitis has been described little in patients with reactive arthritis ( $R e A)$, and almost not mentioned in relation to inflammatory bowel disease (IBD)related arthritis or psoriatic arthropathy (PsA). We report herein two patients with known PsA who developed aortitis and review the relevant literature.

\section{Case Report \#1}

A 66-year old woman with a medical history of moderate arterial hypertension, coronary artery disease and PsA was hospitalized because of persistent chest pain of one week duration, localized to the upper retrosternal area and radiating to her neck and upper back. PsA, affecting medium and large joints in an oligoarticular/asymmetric pattern, had been diagnosed in this patient 12 years ago and was fully controlled by etanercept monotherapy in the preceding two years. On admission, physical examination revealed heart rate of 90 beats/min, arterial blood pressure of 150/90 $\mathrm{mmHg}$ and normal body temperature. Other physical findings were unremarkable. Electrocardiography (ECG) and trans-thoracic echocardiography studies were consistent with mild left ventricular hypertrophy, and there was no evidence of an acute coronary event nor pericarditis. Laboratory work up showed normal levels of serum I-troponin, elevated CRP of $71 \mathrm{mg} / \mathrm{dL}$ (normal limit up to $6 \mathrm{mg} / \mathrm{dL}$ ), and ESR of $90 \mathrm{~mm} / \mathrm{h}$. Computed tomographic (CT) angiography showed findings suggesting aortitis and periaortitis of the upper thoracic and infrarenal aorta (Figure 1A,B). The patient denied clinical signs of giant-cell arteritis, such as headaches, scalp hypersensitivity, jaw claudication or vision impairment. The physical examination of temporal, carotid, subclavian, axillary and brachial arteries as well as full ophtalmological examination did not reveal any abnormality suspicious for giantcell arteritis. The biopsy of the temporal artery was not performed. The serum level of IgG4 was normal $(0.08 \mathrm{mg} / \mathrm{mL}$, normal up to 0.214 $\mathrm{mg} / \mathrm{mL}$ ).

The patient started treatment with intravenous methylprenisolone in a dose of $1 \mathrm{gr}$ daily for 3 consecutive days, followed by 0.5 $\mathrm{mg} / \mathrm{kg}$ oral prednisone with fast resolution of clinical symptoms of aortitis. Etanercept was dicontinued and monthly infusions of tocilizumab in the dose $8 \mathrm{mg} / \mathrm{kg}$ started. Prednisone was gradually tapered down. Six months after admission the patient was in clinical and laboratory remission and off glucocorticosteroids. Repeated imaging demonstrated progressive regression in the findings of aortitis (Figure 1C-F).
Correspondence: Gleb Slobodin, Internal Medicine A, Bnai Zion Medical Center, Haifa 31048, P0 Box 4940, Israel.

Fax: +972.483.59790.

E-mail: gslobodin@yahoo.com

Key words: psoriatic arthropathy, spondyloarthritis, aortitis, vasculitis.

Contributions: GS, study planning, data acquisition, data analysis, writing the manuscript; AK, data acquisition, data analysis, writing the manuscript; RD, IR, study planning, data analysis, manuscript revision; NB, MR, data analysis, manuscript revision; LK, data acquisition, manuscript revision; M0, study planning, manuscript revision.

Conflict of interests: the authors declare no potential conflict of interests.

Received for publication: 30 July 2014.

Revision received: 6 October 2014.

Accepted for publication: 11 October 2014.

This work is licensed under a Creative Commons Attribution NonCommercial 3.0 License (CC BYNC 3.0).

(OCopyright G. Slobodin et al., 2014

Licensee PAGEPress, Italy

Rheumatology Reports 2014; 6:5579

doi:10.4081/rr.2014.5579

\section{Case Report \#2}

A 68-year old woman with a history of arterial hypertension and PsA presented to the emergency room because of recurrent bouts of retrosternal chest pain, with the last episode lasting for about 3 hours. PsA had been diagnosed in this patient 25 years previously, involving the MCP and DIP joints in an asymmetric pattern, and was partially controlled by sulfasalazine and methotrexate. On admission, physical examination was significant only for a diastolic murmur, grade I/IV, over the aortic valve. The patient's serum I-troponin level was normal, while serum CRP level was $52 \mathrm{mg} / \mathrm{dL}$. The ECG and chest roentgenograms were normal. Echocardiography demonstrated calcified aortic valve and mild aortic regurgitation. The patient underwent CT angiography of the chest, which showed thickened aortic wall suggesting the aortitis of thoracic aorta (Figure 2). On further examination, no clinical features, such as new headache, jaw claudication or visual changes, typical for giant cell arteritis were disclosed. Temporal artery biopsy was scheduled, but declined by the patient. Treatment with $1 \mathrm{mg} / \mathrm{kg}$ of prednisone and adalimumab in the dose of $40 \mathrm{mg}$ every other 
week was initiated with rapid and long-term response. The glucocorticoids were tapered down gradually over the next year, and the patient did not show clinical or laboratory signs of the activity of vasculitis. Magnetic resonance angiography (MRA) of the thoracic aorta, performed 9 months later, was considered normal.

\section{Discussion}

Non-infectious inflammation of the aortic wall may be a part of many systemic rheumatic disorders, as well as be a separate idiopathic disease. ${ }^{2}$ Timely diagnosis of aortitis is challenging in many patients, primarily because of the absence of specific clinical manifestations and pathognomonic laboratory signs. The early diagnosis of aortitis, however, may be critical for effective treatment and prevention of possible complications. A high index of suspicion based on the knowledge of both prevalence and presentations of aortitis in patients with different rheumatic disorders and timely referral of the patients for appropriate imaging by a rheumatologist are cornerstones of the early diagnosis of aortitis. ${ }^{1}$

The comprehensive imaging of aortitis should be able to assess the components of the aortic wall and peri-aortic structures in addition to the imaging of the lumen of aorta. ${ }^{2}$ Widely available CT angiography is accurate for the assessment of the aortic lumen and calcifications of the aortic wall, and can detect aortic wall thickening and, sometimes, periaortic haziness in the cases of aortitis, but is usually insufficient for the high resolution aortic wall imaging or evaluation of the activity of inflammation. MRA is frequently regarded as a modality of choice for the imaging of aortitis, providing excellent resolution of the aortic wall as well allowing identification of the areas of active inflammation within the aortic wall, which may manifest as wall edema or enhancement. Recent studies, however, suggest that the 18-fluorodeoxyglucose positron emission tomography may be the most specific (up to $100 \%$ specificity) nowadays available tool for the assessment of disease activity of aortitis, particularly when used in combination with CT angiography or MRA. ${ }^{2}$

Spondyloarthritides, with AS, ReA, IBDrelated arthritis, and PsA as the main representatives of the group, are traditionally counted as a prototypical group of arthritides accompanied by aortitis. Of those, only AS-related aortitis, however, has been characterized systematically since its first description in $1956 .^{3}$ As reviewed recently, ${ }^{4}$ aortic disease in AS may occur in both late and, less frequently, in the early phase of the disease and manifests usually in one of two forms: the first is inflamma- tion of the aortic root and ascending aorta, typified by presence of lymphocytic and plasma cell infiltrates in vasa vasorum, as well as aggregates of the mononuclear cells in the media, resulting in the destruction of the elastic tissue and fibrosis. This form of aortic involvement manifests mainly by insufficiency of the aortic valve and can be readily diagnosed with echocardiographic techniques. The second variant of aortic disease in AS is chronic peri-aortitis of the abdominal aorta. Predominant inflammation of the outer aortic layer with infiltration by lymphocytes, plasma cells and macrophages combined with the development of fibrotic tissue, rich in type 1 collagen and non-proliferating fibroblasts is typical. Chronic peri-aortitis manifests usually by abdominal, back, or flank pain and/or constitutional symptoms with elevation of ESR/CRP and is best diagnosed by CT or magnetic resonance imaging. ${ }^{4}$ Additionally, case studies of the co-incidence of AS with aortitis, diagnosed as Takaysu's arteritis, sometimes with typical stenotic lesions, have been repeatedly published in the medical literature over years, raising the question of the pathogenetic

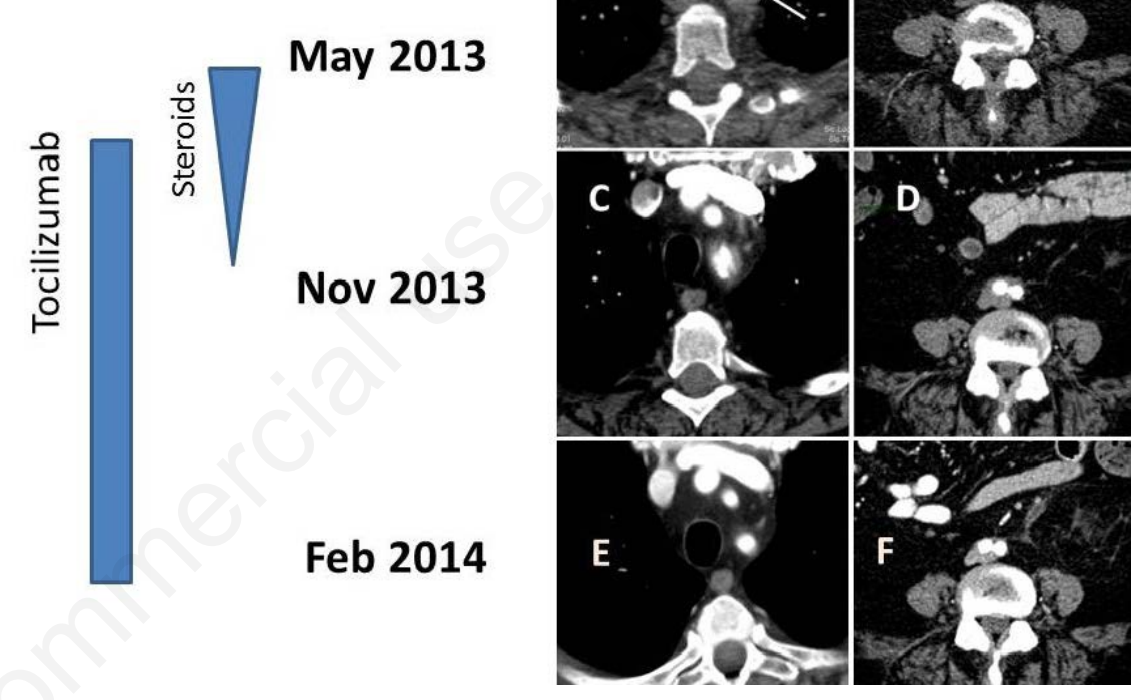

Figure 1. Computed tomography scans of patient 1, axial sections. Irregular concentric thickening of the aortic wall and periaortic haziness around the segment of thoracic descending aorta (A) and periaortic infiltration of the lower aortic segment involving the bifurcation (B) at the time of diagnosis are shown (white arrows). Regression in the burden of aortitis after treatment with tocilizumab, $6(\mathrm{C}, \mathrm{D})$ and $9(\mathrm{E}, \mathrm{F})$ months later.

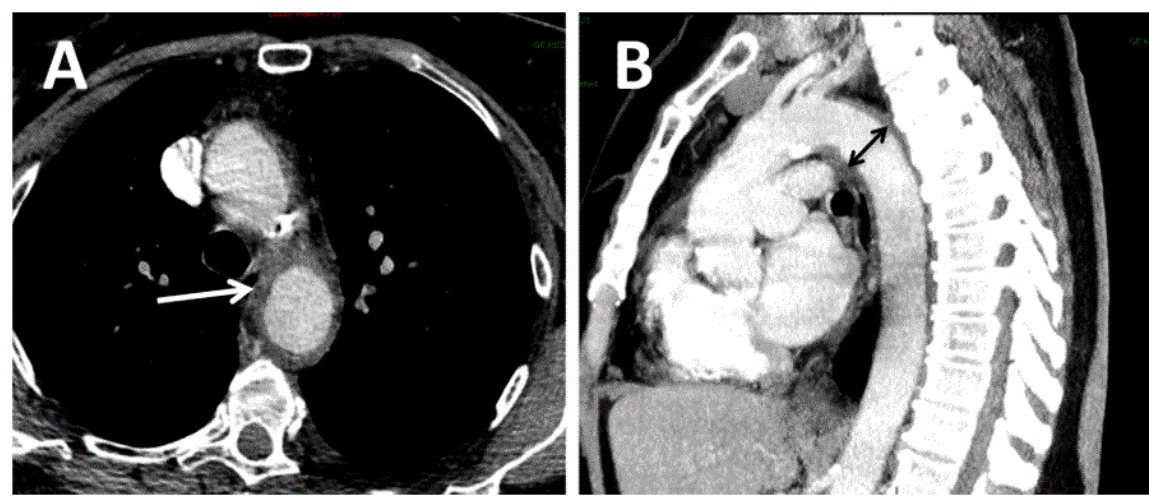

Figure 2. Computed tomography scans of patient 2, axial (A) and saggital (B) sections. Thickened aortic wall of the aortic root and upper part of thoracic descending aorta are shown (arrows). 
Table 1. Characteristics of patients with psoriatic arthropathy and aortitis, reported in the literature.

\begin{tabular}{|c|c|c|c|c|c|c|c|c|}
\hline Age & Sex & $\begin{array}{l}\text { Duration } \\
\text { of PsA }\end{array}$ & Form of PsA & $\begin{array}{l}\text { Skin } \\
\text { psoriasis }\end{array}$ & $\begin{array}{l}\text { Presentation of } \\
\text { aortitis }\end{array}$ & $\begin{array}{l}\text { Distribution and } \\
\text { complications } \\
\text { of aortitis }\end{array}$ & $\begin{array}{l}\text { HLA } \\
\text { B27 }\end{array}$ & Ref. \\
\hline 40 & M & 6 years & $\begin{array}{l}\text { Spinal + psedorheumatoid + } \\
\text { distal interphalangeal }\end{array}$ & Plaque and nail & Dyspnea & $\begin{array}{l}\text { Stenosis of subclavian } \\
\text { and renal arteries }\end{array}$ & - & 11 \\
\hline 60 & M & 10 years & $\begin{array}{l}\text { Spinal+ pseudorheumatoid + } \\
\text { mutilans }\end{array}$ & $\begin{array}{l}\text { Plaque and nail } \\
\text { regurgitation }\end{array}$ & Chest pain and dyspnea & $\begin{array}{l}\text { Ascending aortitis } \\
\text { with aortic }\end{array}$ & + & 12,13 \\
\hline 22 & $\mathrm{~F}$ & 2 years & $\begin{array}{l}\text { Oligoarthritis }+ \\
\text { distal interphalangeal }\end{array}$ & Plaque and nail & Fever, high ESR/CRP & Thoracic descending aortitis & - & 14 \\
\hline 66 & $\mathrm{~F}$ & 12 years & Oligoarthritis & Plaque & Chest pain, high ESR/CRP & $\begin{array}{l}\text { Thoracic descending } \\
\text { aortitis and periaortitis }\end{array}$ & $\mathrm{n} / \mathrm{a}$ & \\
\hline 68 & $\mathrm{~F}$ & 25 years & $\begin{array}{l}\text { Pseudorheumatoid + } \\
\text { distal interphalangeal }\end{array}$ & Plaque and nail & Chest pain, high ESR/CRP & $\begin{array}{l}\text { Aortic root and thoracic } \\
\text { descending aortitis }\end{array}$ & - & \\
\hline
\end{tabular}

PsA, psoriatic arthropathy; -, negative; +, positive; na, not available; ESR, erythrocyte sedimentation rate; CRP, C-reactive protein.

link between these two disorders. ${ }^{5}$

Similar to that described in AS, ascending aortitis with aortic regurgitation has been the most frequently reported pattern of aortic involvement in ReA. In 49 cases of such involvement, which were reviewed recently, the average time from the diagnosis of arthritis to the appearance of aortic valvular defect was 13 years, while more than $20 \%$ of patients developed aortitis within the first year after the diagnosis of the ReA. ${ }^{6}$ Distal aortitis has been rarely reported in patients with ReA and may also manifest by hemodynamically significant stenotic lesions of the aorta and its branches with peripheral ischemia. ${ }^{7}$

Thirty-seven cases of aortitis associated with IBD were summarized by Kusunoki et al. ${ }^{8}$ The authors calculated that co-existence of these diseases can be estimated to be 1 in 10 million individuals based on chance alone, and suggested the presence of a pathogenetic link between aortitis and IBD. A series of 44 patients with Takayasu's arteritis, which included 4 patients with known Crohn's disease, strengthened further the assertion that the Takayasu-Crohn association is not fortuitous. ${ }^{9}$ In our literature search, we were able to find only one case describing development of aortitis in a patient with IBD-related arthritis, however. Aortitis in this single patient was characterized by the presence of non-necrotizing granulomatous lesions, containing multinuclear giant cells, within the aortic wall. ${ }^{10}$ Only 3 cases of aortitis in patients with PsA have been described in detail in the medical literature. ${ }^{11-14}$ The data available on these 3 cases as well as the data on the 2 patients reported herein are summarized in Table $1 .^{11-14}$ It can be appreciated that no specific pattern of joint involvement, nor particular skin manifestation of psoriatic disease were associated in these PsA patients with the development of aortitis.
The majority of these patients, however, had long-standing PsA and one patient had been treated with an anti-TNF agent prior to the development of the aortic disease. Chest pain, dyspnea and elevation in CRP/ESR, not related to the active joint disease, were the main presenting signs of aortitis in these patients. It seems that all aortic segments can be involved, and complications, such as insufficiency of the aortic valve and stenosis of the major aortic branches may also develop. In this regard, the appropriate imaging in a patient, suspicious for aortitis, should include the entire aorta with its main branches and provide the resolution of the aortic wall as well as peri-aortic tissue, depicting the areas of the active disease.

The rarity of the reports on the association of large vessel vasculitis with PsA may naturally be seen as just unrelated co-incidence of these disorders in the same persons. However, a recent large epidemiological study on the coincidence of psoriasis and psoriatic arthropathy with other autoimmune and rheumatic disorders, reported the significantly higher prevalence (4.8-fold) of giant cell arteritis in patients with PsA compared to the general population. ${ }^{15}$ The suggestion by the authors of shared immune pathways involved in the pathogenesis of the two diseases may be further supported by recently published data of a higher than anticipated prevalence of spondyloarthritis in patients with known large vessel vasculitis. ${ }^{16}$ While the detailed description of these shared immune pathways are still to be elaborated, it seems that IL12B gene products may be critically involved in these common pathogenetic mechanisms. The genetic association involving the IL12B locus, which encodes for the common P40 subunit of IL-12 and IL-23, has been established in studies involving both patients with Takayasu arteritis and spondyloarthritides, such as PsA and AS. ${ }^{17-20}$

\section{Conclusions}

In summary, aortitis may be seen in patients with PsA and can involve any segment of thoracic or abdominal aorta. Chest pain, dyspnea and elevation in CRP/ESR, not related to the active joint disease, are main presenting signs of aortitis in these patients. The common genetic associations in IL12B locus in both spondyloarthritides and aortitis (Takaysu arteritis) may serve as a basis for the respective clinical associations of these disorders.

\section{References}

1. Slobodin G, Naschitz JE, Zuckerman E, et al. Aortic involvement in rheumatic diseases. Clin Exp Rheum 2006;24:S41-7.

2. Gornik HL, Creager MA. Aortitis. Circulation 2008;117:3039-51.

3. Luccerini T, Cecchi E. Ankylosing spondylitis with aortitis and insufficiency of the aorta. Minerva Med 1956;47:43-50.

4. Palazzi C, Salvarani C, D'Angelo S, Olivieri I. Aortitis and periaortitis in ankylosing spondylitis. Joint Bone Spine 2011;78:4515.

5. Soubrier M, Dubost JJ, Demarquilly F, et al. Takayasu disease and ankylosing spondylarthritis: a probably non-fortuitous association. Presse Med 1997;26:610.

6. Brown LE, Forfia P, Flynn JA. Aortic insufficiency in a patient with reactive arthritis: case report and review of the literature. HSSJ 2011;7:187-9.

7. Morgan SH, Asherson RA, Hughes GR. Distal aortitis complicating Reiter's syndrome. Br Heart J 1984;52:115-6.

8. Kusunoki R, Ishihara S, Sato M, Sumita Y, 
et al. Rare case of Takayasu'a arteritis associated with Crohn's disease. Intern Med 2011;50:1581-5.

9. Reny JL, Paul JF, Lefebvre C, et al. Association of Takayasu's arteritis and Crohn's disease: Results of a study on 44 Takayasu patients and review of the literature. Ann Med Interne 2003;154:85-90.

10. Anwar S, Saboeiro GR, Yang A, et al. Largevessel granulomatous vasculitis in Crohn's disease. HSSJ 2010;6:206-13.

11. Fukuhara K, Urano $\mathrm{Y}$, Akaike $\mathrm{M}$, et al. Psoriatic arthritis associated with dilated cardiomyopathy and Takayasu's arteritis. Br J Dermatol 1998;138:329-33.

12. Roller DH, Muna WF, Ross AM. Psoriasis, sacroiliitis, and aortitis: an echocardiographic mimic of aortic root dissection.
Chest 1979;75:641-3.

13. Muna WF, Roller DH, Craft J, et al. Psoriatic arthritis and aortic regurgitation. JAMA 1980;244:363-5.

14. Tufan A, Engin Tezcan M, Kaya A, et al. Aortitis in a patient with psoriatic arthritis. Mod Rheumatol 2012;22:774-7.

15. Makredes M, Robinson D Jr, Bala M, Kimball AB. The burden of autoimmune disease: a comparison of prevalence ratios in patients with psoriatic arthritis and psoriasis. J Am Acad Dermatol 2009;61: 405-10.

16. Ernst D, Baerlecken N, Schmidt R, Witte T. Large vessel vasculitis and spondyloarthritis: coincidence or associated diseases? Scand J Rheumatol 2014;43:246-8.

17. Saruhan-Direskeneli G, Hughes T, Aksu K, et al. Identification of multiple genetic susceptibility loci in Takayasu arteritis. Am J Hum Genet 2013;93:298-305.

18. Terao C, Yoshifuji H, Kimura A, et al. Two susceptibility loci to Takayasu arteritis reveal a synergistic role of the IL12B and HLA-B regions in Japanese population. Am J Hum Genet 2013;93:289-97.

19. Liu Y, Helms C, Liao W, et al. A genomewide association study of psoriasis and psoriatic arthritis identifies new disease loci. PLoS Genet 2008;4:e1000041.

20. Wong $\mathrm{RH}$, Wei JC, Huang $\mathrm{CH}$, et al. Association of IL-12B genetic polymorphism with the susceptibility and disease severity of ankylosing spondylitis. J Rheumatol 2012;39:135-40. 